\title{
O Direito muçulmano
}

\author{
Lino de Morais Leme \\ Catedrático jubilado da Faculdade de \\ Direito da Universidade de São Paulo.
}

\section{Organização política das tribus árabes}

1. As tribus da Arábia estavam divididas em "gentes", recordando a antiga organização de Roma. A tribu do Khoreichitas, que povoava a região de Meca, compreendia várias "gentes", entre as quais a de Ebou-Hachims e a de Ebou-Sofiani. Meca era o centro religioso em que era adorada a Kaaba (pedra preta) ${ }^{1}$.

Os antepassados de Mahomet, o Profeta, (em árabe Mohammed, o "Louvado"); nascido em 571 e falecido em 632 , em consequência de uma febre que apanhou na pere-

1. Segundo a tradição, primitivamente fixada no Céu, onde os anjos, conduzidos pelo arcanjo Gabriel, iam fazer procissão em torno dela. A mesquita santa (Masdjid-el-Haron), construida por Seth, filho de Adão, destruida pelo dilúvio, foi reedificada por Abrahão, no próprio logar em que esteve prestes a sacrificar, a Jehovah, seu filho Isaac, e no mesmo local em que se elevava a mesquita de Seth. O arcanjo Gabriel trouxe a Abrahão a pedra da Kaaba, que foi colocada no recinto da nova mesquita.

Como cada uma das tribus árabes tinha os seus deuses, e sendo o templo da Kaaba o grande santuário, achavam-se aí representados por estátuas ou imagens, um grande número de divindades. Segundo os historiadores muçulmanos, aí se encontraram 360 imagens, entre as quais as de Cristo e da Virgem Maria, explicável porque diversas tribus árabes se tinham convertido ao Cristianismo.

Essa pedra não é senão um dos números betiles. que em todos os tempos foram adorados como divindades, pelos semitas. 
grinação a Meca, tinham aí dominado desde Qoussa $\left(4 .^{\circ}\right.$ avô de Mahomet), que, após uma luta sangrenta, tomou posse das chaves do Keabé, num tempo em que o recinto respeitado - a extensão do terreno que veiu a formar depois a cidade de Meca - era ainda deshabitada. Qoussa fundou e povoou Meca. Abd-ul-Montaleb, o avô do Profeta, não tinha senãọ a administração da água do poço de Zem-Zem e a guarda das chaves do Keabé.

O pai de Mahomet, Abd-Allah, que fazia o comércio de caravana com a Síria, morreu antes do nascimento do filho; e a mãe Amina Mottaleb, pouco tempo depois. A educação do Profeta foi iniciada pelo avô; após a morte do mesmo, foi continuada por seu tio Abou-Taleb, que também fazia o comércio de caravanas.

Deixando o serviço do tio para tomar a direção dos negócios de rica viuva de Meca, Khadija. Mahomet com ela se casou; tinha êle, então 25 anos.

\section{A missão de Mahomet}

Aos 40 anos, ele teve sua primeira revelação: o anjo Gabriel lhe apareceu numa gruta em que êle costumava retirar-se, e, anunciando-lhe sua missão, revelou-lhe os seus primeiros versiculos do $96 .^{\circ}$ capítulo (surate) do Corão, em que estão dispostos não na ordem cronológica, mas na da extensão.

A missão do Profeta foi aceita imediatamente por sua mulher, por Ali, filho de Abou-Taleb, que Mahboet recolhera, por Abou-Behr e por Osman. O Profeta lhes deu o nome de mouslim ("devotado a Deus"); do plural dessa palavra resultou muçulmano. Islamismo vem de Islam, palavra árabe que significa "resignação".

Em 621, Medina se converteu espontâneamente ao Islamismo. E os Ehou-Sofians, aproveitando-se da circunstância, declararam guerra a Mahomet, que, no entanto, protegido por seu tio, Abou-Taleb, que sucedera a Abdu-el- 
Mutaleb, como chefe da gens, continuou a exercer sua missão na cidade santa da Arábia idólatra. Morrendo o tio, o Profeta teve de emigrar; a cidade de Iatreb lhe abriu as portas, e, após a hegira (em árabe hidjret "fuga") se chamou Medina, a cidade do Profeta (Medinétoul-Nebi).

Conquistada Meca, Mahomet fez destruírem todos os ídolos. Em breve, dominou toda a Arábia e se decidiu a empreender a conquista do Égito, da Grécia e da Pérsia. Um dos sucessores imediatos do Profeta, Omar Faruk, estendeu, em dez anos, o domínio do islamismo, dos confins da China ao estreito de Gibraltar. Hoje, o número dos islamitas é de mais ou menos 300.000.000.

\section{A religião muçulmana}

A religião cristã tem em vista apenas a moral: "Dai a Cesar o que é de Cesar e a Deus o que é de Deus", disse Jesus Cristo. A religião muçulmana, porém, reune o espiritual e o temporal, pois contém uma legislação completa, fundada na revelação; é o Corão, dividido em 132 capítulos (sureta), subdivididos em versículos (ayets). Foi ditado em vida de Mahomet. Escreveram-nos sôbre papiros, ossos de ombros de carneiros e pełes de camelos. No califado de Abou-Behr, sucessor imediato do Profeta, foi feita uma edição completa dêsse livro.

\section{As fontes de legislação muçulmana}

As fontes da legislação muçulmana são: a) o Corão; b) a conduta do Profeta (Sunna) (ou Jadis = tradição); c) a opinião unânime dos sucessores imediatos do Profeta, a qual foi dada em concilio (Idjimâ), tendo importância capital a das tres primeiras gerações islamitas: a dos companheiros do Profeta (Ashab); a dos adeptos (Tabün) os que conheceram os companheiros; a dos seguidores ( $t a$ - 
basi), que conheceram os adeptos; d) a analogia admitida pelos jurisconsultos (Kiyassifrgha).

A conduta do Profeta (unnat) era representada por suas palavras e atos e a aprovação explícita ou tácita que êle dava às palavras e atos de outrem. Dela ha seis repositórios autênticos. O califa Omar Faruk, por exemplo, não distribuíra, aos guerreiros do Islam, as terra da Síria: confirmou-as aos antigos proprietários e sujeitou-as a um imposto superior ao dízimo. Levantando-se murmúrios, o califa reuniu o concílio e perguntou, aos "companheiros", se tinham conhecimento da forma pela qual o Profeta tinha disposto das terras pertencentes aos israelitas de Haïber. Êles responderam que Mahomet confirmara os antigos proprietários na posse das terras, impondo, porém um imposto maior do que o dízimo e proporcional à fertilidade do solo. $\mathrm{E}$ assim foi reconhecido que as disposições tomadas pelo califa eram perfeitaniente legais.

A analogia admitida pelos jurisconsultos consistia em aplicar, a um fato novo ou conhecido, porém não ainda juridicamente apreciado, a norma referente a um outro fato já legalmente qualificado. A aguardente, por exemplo, era desconhecida no Hedjaz, e não se encontra, nas fontes primeiras, nenhuma disposição, proibindo-lhe o uso. Os jurisconsultos do Islam lhe aplicaram as disposições legais contidas no Corão, sôbre o vinho, admitindo analogia, com o mesmo, dos efeitos tóxicos da nova bebida.

\section{A lei muçulmana}

A lei é o conjunto de ordens que o legislador dirige ao homem.

Os deveres que ela impõe compreendem os para com o Criador e os para com os semelhantes, todos resultantes dos direitos de Deus sôbre os homens.

Os deveres do homem para com Deus são designados como "imposições piedosas" (teúelufati ibadéyé), e compreendem quatro seções: a) a primeira abrange aqueles 
cuja omissão cria, meste mundo, um dano que afeta apenas a sociedade - a contribuição da esmola, o dízimo e o dízimo aumentado (Também o muçulmano deve pagá-lo, quando adquire terras ao mesmo sujeitas); b) a segunda, aqueles cuja omissão acarreta dano para a sociedade e para o indivíduo - a peregrinação, a guerra santa; c) a terceira, aqueles que, não cumpridos, não acarretam, neste mundo, nenhum dano, quer à sociedade quer ao indivíduo - a purificação, a prece, o jejum; d) a quarta, aqueles que incumbem a toda a sociedade islamita, mas que basta sejam cumpridas por alguns - o enterro dos mortos, a prece pelo repouso de suas almas.

\section{Partes constitutivas da legislação muçulmana}

As partes constitutivas da legislação muçulmana (merchâuat = cousas da lei) são em número de cinco: 1) as crencas (itigadat); 2) as práticas religiosas (ibadat); 3) as obri gações e contratos (melat);4) as ações puníveis (uquabát), 5) as expiações (keferat).

As crenças são em número de cinco: 1) em Deus (Allahuiman); 2) nos anjos (Meliaikeyeiman); 3) nos livros santos (Kitaba iman); 4) no Profeta (Ressoulé iman); 5) no Juízo final (Yeomul-ah-reté iman).

As práticas religiosas são em número de cinco, divididas em tres categorias: a) os atos de piedade exclusivamente corpóreos: 1) a prece (selint);2) o jejum (savm); 3) a guerra santa (djehad); b) os atos de piedade exclusivamente pecuniários; 4) a contribuição da esmola (zekate), à qual se liga o dízimo (ouckre); c) os atos de piedade, de caráter mixto (corpóreos e pecuniários); 5) a peregrinação (Hadje).

As obrigações e contratos são em número de cinco: 1) os com equivalência (mauavazat); 2) os casamentos ( $\mathrm{mu}$ nakadat); 3) o parentesco (mouhassemat);4) os depósitos (amanat); 5) as associações (cherekat). 
As ações puníveis com penas graves são em número de cinco; 1) o assassínio com premeditação (gatli gasdi), punível com a pena de talião (gisses); 2) o roubo qualificado (Sirgat), punido com perda da mão (Gat Yed);3) o adultério (Zina), punido segundo as condições dos culpados, pela lapidação (Redjm) ou a bastonada (djeldè); 4) o insulto à honra das mulheres (gagf,) punido com oitenta bastonadas; 5) a abjuração (irtidad), punido com a morte (gatl).

As expiações são em número de cinco: 1) a pelo assassinato (kefareti - gatl) ; 2) pelo insulto à mulher legítima, empregando-se expressões que assimilam a esposa a uma parenta próxima, tal como a mãe (kefareti - kahar) - é uma renúncia às relações legais do homem com a esposa; 3) a pela ruptura irregular do jejum (kefareti iftar); 4) a pelo juramento islado (kefareti jemin); 5) a pelos erros cometidos durante a peregrinação (kefareti-khatiati-hadje)

\section{Concepções religiosas e éticas}

Deus é o juiz do homem. Êle ordena as ações belas. "As ações feias" são proibidas.

A beleza e a feiura são o efeito das apreciações e juizos da razão humana, ou o resultado das apreciações do Juiz (Deus), expressas pela lei que os profetas revelaram aos povos? Diversas opiniões foram manifestadas, entre as quais a de Hassan el Basri, o chefe da escola ultra-conservadora, para quem a beleza e a feiura são os efeitos (assars), da ordem do legislador, isto é, uma ação é bela porque Deus a recomendou, feia, porque êle a proibiu.

Nos primeiros tempos, as funções de juiz foram exercidas pelo próprio Profeta e pelos quatro califas que the sucederam. O califa delega seus direitos judicantes a um homem sábio, experimentado e de uma conduta ilibada, cuja consciência foi formada segundo os preceitos da religião e da moral. 
O sábio que exerce as funções de pretor (mufti), e que por suas opiniões doutrinárias (fetava = fórmulas), guia o juiz no cumprimento de suas funções, deve ter conhecimento profundo da língua árabe, que é a língua do direito, além de outros conhecimentos especificados.

\section{Divisão do mundo muçulmano}

O mundo muçulmano está dividido entre os Sunnitas e os Chiitas ou Imamitas: os primeiros reconhecem os califas, na ordem de sua sucessão histórica, enquanto que os segundos sòmente admitem, como califas legitimos, o genro e primo do Profeta, Ali, quarto califa, e seus descendentes.

A Sunna se divide em quatro escolas ou ritos, assim chamadas do nome de seus fundadores ou imann (beira' do templo, chefe ou guia) - $10^{\circ}$ ) hanefita ou janefita, por Abou Hanifa (702-772), que domina no antigo império otomano, na Asia Central, no Pakistão, e entre os muçulmanos da India;.$^{\circ}$ ) malekita, por Malek (722-795), na África do Norte francesa, $3 .^{\circ}$ ) chafeita, por Mhafei (772-826), na Insulíndia; e $4 .^{\circ}$ ) hambalita, por Hambal (786-863), na Arábia central e oriental e no Alfganistão.

Entre as seitas que os sunitas consideram heréticas, estão os chiitas ou xiitas, sectários de Ali, no Irã e nos̀ estabelecimentos franceses da Índia; os nahabitas, na Arábia saudita, que não admitem como fontes do direito apenas' o Corão e a Sunnah, e os abaditas, ou harigitas, estreitamente ligados aos vahabitas, na costa da África Oriental, no Zanzibar e em parte da África do Norte francesa (Mzab e Djerba).

\section{Aplicação do direito muçulmano}

Aos muçulmanos exclusivamente, nos países em que dominem, se aplica o direito muçulmano; aos não muçulmanos, o direito positivo, devendo eles pagar um im- 
posto de capitação, em sinal de submissão, ou dependência, não podendo ter propriedade, mas apenas posse, embora hereditária e transmissivel, e ocupando uma posição diversa no direito criminal, quanto à pena e ao testemunho. Perde-se a qualidade de muçulmano pela apostasia, mas readquire-se pela volta aos cultos muçulmanos. Um prazo de tres dias é concedido ao apóstata, para retratar-se. Findo êsse prazo, sem retratação, êle é morto, e seus bens passam para o Tesouro Público, exceto se for escravo, em cujo caso pertencem a seu senhor.

O direito muçulmano admite a poligamia: o homem pode ter quatro mulheres legítimas, com certos direítos e honras, além das concubinas, se êle não se comprometeu a ficar monógamo, bígamo ou trígamo. Os homens são constrangidos ao casamento por meio da prisão e da chibata, quando impúberes. Sendo púberes e sãos de corpo e de espírito, é mister o consentimento. A consumação do casamento dos impúberes é diferida para a puberdade. proibido o casamento entre um muçulmano e um não muçulmano, cessando a proibição, para as mulheres muçulmanas, após a morte do marido, ou o divórcio. Os impedimentos matrimoniais são: a) na linha reta, seja o parentesco legítimo ou ilegítimo; b) entre os criados pela mesma ama e esta, assim como entre seus ascendentes e descendentes; c) entre sogra e genro, sogro e nora, madrasta e genro, padrasto e nora, os quais prevalecem mesmo após a morte ou o divórcio; d) na linha colateral, até o $3^{\circ}$. grau; e) o fato de um homem ter quatro esposas, e o de a mulher ter sido pejada por outro, que não o futuro marido.

Se o marido tem mais de uma mulher, cada uma tem direito a uma habitação separada.

O único regime de bens admitido é o da separação.

O casamento é nulo, se existe algum dos impedimentos apontados. E é anulável se não foi livremente consentido, se contraído com pessôa de condição inferior, se devia ser autorizado, e não foi, se foram feitas estipulações contrárias ao fim do casamento, etc. 
O casamento se dissolve pela morte, apostasia, repúdio. (talak), pelo divórcio por mútuo consentimentō, e por decisão judicial.

A mulher não se pode divorciar senão com autorização de seu marido, ou do juiz, ou ainda com um resgate aceito pelo marido.

O pai pode reconhecer o filho. Basta o reconhecimento para se estabelecer a filiação, se ratificado pelo filho, sendo êle capaz. O reconhecimento pode ser tácito, resultando da conduta do pai para com o filho. A mulher pode reconhecer um filho, sem pai nem mãe conhecidos.

O menor púbere pode dispôr de sua pessôa, mas sòmente aos 25 anos pode gerir seus bens, salvo sendo reco-nhecido apto. A puberdade é presumida aos 15 anos, para ambos os sexos, no rito hanefita; aos 18 anos, no malekita; aos 15 anos para os homens e aos 9 anos para as mulheres, no rito chiita.

O direito de sucessões é muito complicado, compreendendo tres categorias de herdeiros, cada uma subdividida em ordens ou classes. $O$ varão tem um quinhão igual ao de duas mulheres. Não ha o direito de representação. Não se admite a sucessão contratual. Pode a pessôa dispôr deseus bens, por atos inter vivos, mesmo em benefício de quem. pertença a religião diferente, salvo se por doação com o fim de fraudar a proibição de legar a um estrangeiro mais do que a terça parte dos bens da herança. A vocação hereditária e estabelecida em favor dos parentes, do cônjuge sobrevivente, do senhor em relação ao liberto, e, na ausência de herdeiros, ao Tesouro Público (Beit al hal). O direito de um herdeiro eventual pode ser reduzido ou suprimido pela existência de outro herdeiro, mas não podem ser ex̌cluidos completamente os pais, os filhos e o cônjuge. O testador não pode modificar a ordem da sucessão, nem testar em favor de algum herdeiro que tiver no momento de sua morte; e o legado, em havendo herdeiros, não pode exceder a terça parte da herança.

$O$ direito das obrigações, amplamente desenvolvido pelos jurisconsultos, não está no Corão. Recomenda-se que 
os contratos sejam por escrito e com testemunhas, equivalendo o testemunho de duas mulheres ao de um varão. O casamento, o wafh (corresponde a uma fundação), o testamento, figuram entre os contratos. É proibido o empréstimo a juros. É vedada qualquer cláusula que vise fraudar a interdição da usura, do jôgo, da especulação ou mesmo própria a encorajar litígios, desvendar a fraude, a se obrigar levianamente, a assumir-se obrigação estranha ao contrato ou sem causa, ou que permita o não cumprimento da obrigação. São ilícitas as estipulações que impõem uma obrigação sem interêsse para um dos contratantes, como a de não revender o animal, a de emancipar o escravo adquirido ou executar uma obrigação em proveito de terceiro, bem assim as que conferem vantagem, sem equivalente, as que são estranhas à natureza do contrato no qual figuram (Por ex., compra de fazenda, sob a condição de que o vendedor fará um manto, pois combina o contrato de locação de serviços com o de venda; mas a venda da fechadura pode ser subordinada à sua colocação pelo vendedor, por isso que se trata de cláusula conforme à natureza do contrato).

O Corão e o Sunnah reconhecem a plena propriedade das terras mortas (aadia), que o trabalho faz voltarem à vida: "Se alguem restituir à vida uma terra, diz Mahomet, ela lhe pertence" 1 .

Ha os bens Wakouf ${ }^{2}$ - móveis ou imóveis, atribuidőos gratuitamente, durante um periodo determinado ou perpètuamente, por um ou mais muçulmanos maiores, a um ou mais muçulmanos maiores, a um ou mais muçulmanos, ou a família muçulmana e a seus descendentes, ou a uma tribu muçulmana, ou a uma fundação pia do culto muçulmano, ou a uma obra qualquer de interêsse geral para o culto muçulmano. Ésses bens são inalienáveis e os beneficiários

1. Terras mortas são as rurais, que não pertencem a particulares, nem ao conjunto dos súditos do soberano. Essas terras pertencem a Deus.

2. Singular, wakf. Na África do Norte são chamados habbous. 
não tem senão o gôso, salvo cláusula contrária. Entre os direitos reais figuram a superfície e o direito de retenção. o penhor se aplica também aos imóveis (não têm a hipoteca, nem o privilégio do vendeđor, que substituem pela cláusula de retrovenda (não admitida no direito chiita).

A lei islamita não é exclusiva em suas aplicações; ela aceita todas as verdades. Assim, o direito natural e as leis romanas, nada tendo de contráiro ao Corão, são aceitas.

Sendo os países muçulmanos muito diferentes quanto à sua civilização e situação econômica, devem apresentar variações costumeiras e jurisprudênciais, o que foi verifłcado por Morand e Melliot, nas coleções dêsses direitos, que descobriram.

\section{O método para o estudo do direito}

Imami-Azam (Numan) foi o primeiro criador do método para o estudo do direito muçulmano. Ele distingue as ciências da revelação das nascidas da razão, representando estas os conhecimentos que por ela se adquirem, independentemente dạ revelação.

As ciências da revelação compreendem: a) Ciência da linguagem, ou instrumentária, e b) as Ciências da legislacão.

As ciências da legislação ${ }^{1}$ compreendem: 1) Ciência das fontes: a) Ciência do Corão (Ciência da leitura do Corão e Ciência dos comentários do Corão); b) Ciência da conduta do Profeta; II) Ciências deduzidas das fontes: a) Ciência das crenças e das convicções religiosas-Ciência da unidade de Deus e Ciência dos atributos de Deus; b) Ciências das legislações (fiqh): aa) teoria do direito; bb) aplicações do direito.

1. Legislação, diz Imame-Azam, é o conhecimento pelo homem, de seus direitos e deveres. Manifet é o conhecimento aprofundado, exato, e que se obtem - segundo a escola dos jurisconsultos hanefitas pelo estudo da ciência do direito. 
As aplicações do direito se referem às ações humanas: a) tendo um caráter religioso ou social (prece, jejum, contribuição da esmola, guerra santa, direito de paz e de guerra, peregrinação; b) tendo um caráter privađo: aa) relativas aos vivos (casamento, obrigações e contratos (direito civil e comercial), penas (direito penal); bb) relativas aos mortos (direito das sucessões); c) tendo um carater mixto (o dizimo).

Imami-Azam introduziu, no ensino do direito, a filosofia e a moral. A primeira (metafísica) ensina a conhecer as relações entre o homem e Deus e as entre o homem e os outros seres. A moral faz conhecer as relações regulares e corretas que devem existir quer entre os que vivem em sociedade, quer entre o indivíduo e a sociedade: ela forma a consciência do homem e a do juiz e a fortifica, de forma que uma e outra se tornem capazes de distinguir a beleza (legalidade) da feiura (ilegalidade).

\section{Importância do estudo do direito}

O profeta, em vida, deu a mais alta importância ao estudo do direito, estabelecendo disposições em favor dos que a êle se dedicam, dispensando-os de participar da guerra santa (djehad) e procurando prestigiá-los no seio da sociedade, como se vê pelos dois hadis: "Deus, quando quer favorecer um dos seus escravos, o faz apreender o direito" - (Palavra por palavra - "faz dele um jurisconsulto (feqih); "Um jurisconsulto é mais forte contra Satanás, do que mil ignorantes, em ato de prece".

\section{Fechada a porta da interpretação}

No século $X$, naturalmente para evitar a formação de novos ritos, foi fechada a porta da interpretaçăo., Desde então o direito muçulmano vem sendo ensinado de acồrdo: 
com as obras escritas no século XIV. Como diz Seignette. ${ }^{1}$ " $O$ islamismo voltou as costas ao futuro e a face ao passado".

Espíritos cultos têm encarecido a necessidade de se permitirem novos desenvolvimentos ao direito, com as cautelas aconselháveis, lembrando que a interpretação já admitira que, através da letra da lei, se procurasse o seu espírito, bem assim reconhecendo princípios, como o da necessidade e o do bem público.

\section{Código nos países muçulmanos}

Em alguns países muçulmanos, já se organizaram Códigos Civis gerais ou parciais: na Turquia e na Pérsia, Código geral; na Albânia foi adotado, em 1927, o projeto franco-italiano do Código único das Obrigações; no Líbano, um Código de Obrigações e Contratos, estabelecido em 1932, por M. Josserand; e um Código de Propriedade Imobiliária (aplicável também à Síria), em 1939, e um Código de Comércio, em 1946; em Marrocos, quanto ao Direito das Obrigações; no Egito, em 1948, um Código Civil novo, adotado igualmente pela Síria.

O que interessa, porém, não é conhecer os Códigos, com roupagens ocidentais, mas o direito muçulmano, que tem caracteres originais como se viu, e que requer estudo, para se poder comparar a orientação diversa seguida quanto ao Direito, no mundo muçulmano.

1. Na introdução de sua tradução de Lidi Khalil. 